\title{
Endoscopic vacuum-assisted therapy of an infected pancreatic pseudocyst
}

Infected pancreatic pseudocysts are serious complications of acute and chronic pancreatitis [1-3]. Endoscopic vacuumassisted therapy (EVAT) is a reliable treatment for abscesses that are accessible endoscopically $[4,5]$. We report the first case in which EVAT was used in the treatment of an infected pancreatic pseudocyst.

A 28-year-old woman was admitted with a severe inflammatory response syndrome (SIRS) due to a $20 \mathrm{~cm}$ infected pancreatic pseudocyst. We performed endoscopic ultrasound-guided transgastric puncture, dilated the transgastric access by balloon catheter (Olympus Medical Systems, Hamburg, Germany), and drained the pseudocyst using three 10-Fr double-pigtail endoprotheses (Medi-Globe, Achenmühle, Germany) and a nasocystic tube (PBD21Z; Olympus, Tokyo, Japan).

Over the next 6 days, $1500 \mathrm{~mL}$ normal saline per 24 hours was continuously injected into the cyst via the nasocystic tube. On the second and fifth days after the initial drainage, we again dilated the transgastric access to $14 \mathrm{~mm}$ using a balloon catheter, intubated the cyst with the endoscope (GIF Q180, Olympus, Tokyo, Japan), and removed infected fluid and tissue in a Dormia basket (Endoflex, Voerde, Germany; $\bullet$ Fig. 1).

The cyst was therefore cleaned and the SIRS resolved; however, 7 days after the initial drainage, the pseudocyst had still not completely collapsed ( $\bullet$ Fig. 2 ).

We removed all the endoprotheses, dilated the access to $16 \mathrm{~mm}$ and started EVAT following insertion of the Endo-SPONGE system (B. Braun, Melsungen, Germany). The size of the sponge was adjusted according to the local topography and placed into the cyst by means of a grasping forceps and guide wire (Jagwire; Boston Scientific, Miami, USA; $\bullet$ Figs. 3 and 4 ).

The suction tube was extended with a nasogastric tube and secretions were continuously evacuated with a suction of $120 \mathrm{~mm} \mathrm{Hg}$ (16 kPa). All procedures were performed whilst the patient was under conscious sedation with midazolam and propofol.

The Endo-SPONGE system was replaced on the third day. The wall of the cyst had become very well supplied with blood and

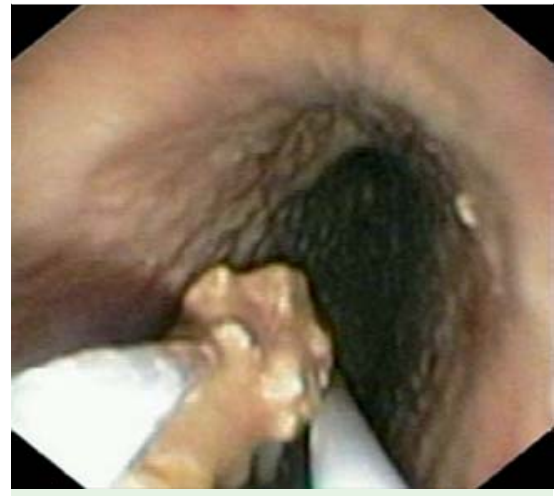

Fig. 1 Endoscopic image of the infected pancreatic pseudocyst at the beginning of treatment with infected tissue in a Dormia basket, which was transferred into the stomach.

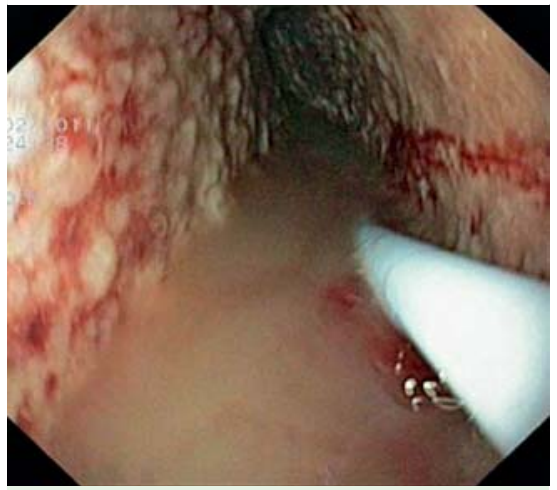

Fig. 2 Endoscopic image of the infected pancreatic pseudocyst, 7 days after initial drainage and removal of the necrotic tissue, prior to the commencement of endoscopic vacuum-assisted therapy (EVAT).

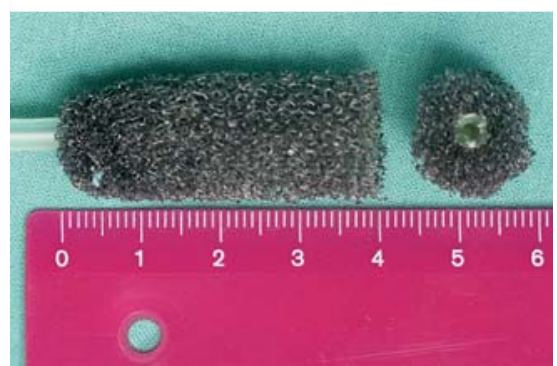

Fig. 3 Image of the Endo-SPONGE, $40 \mathrm{~mm}$ in length and $14 \mathrm{~mm}$ in diameter.

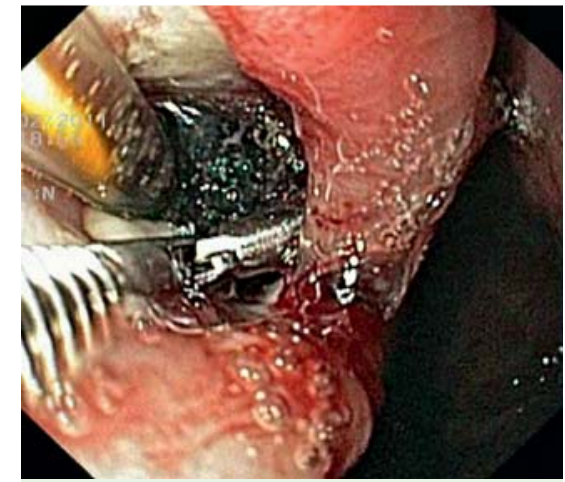

Fig. 4 Endoscopic image of the sponge in situ with the visible end in the stomach wall, the yellow-black guide wire inside the suction tube for guidance during implantation, and the grasping forceps.

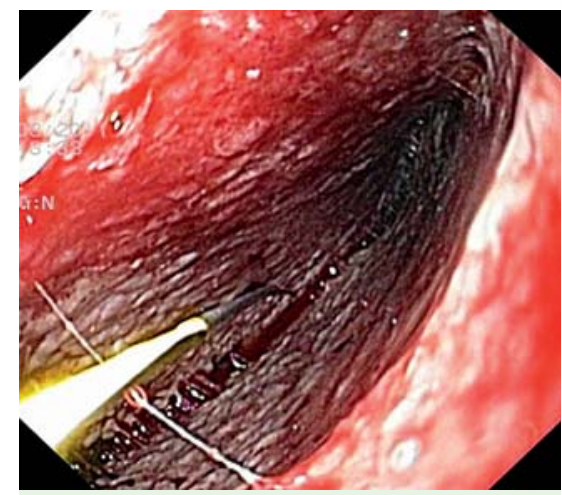

Fig. 5 Endoscopic image showing the visible guide wire and the inner cystic wall with clean granulation tissue on the third day of endoscopic vacuum-assisted therapy (EVAT).

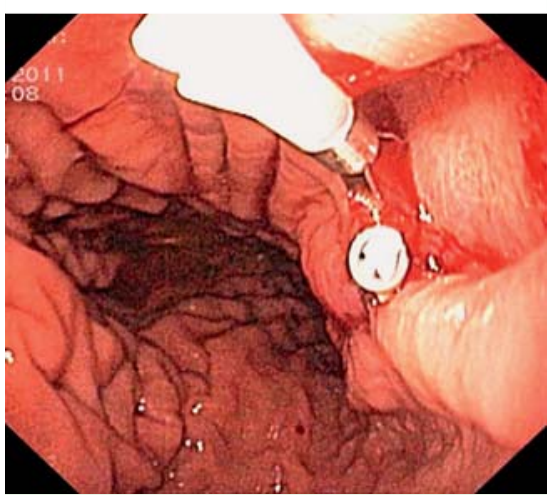

Fig. 6 Endoscopic image of the stomach showing the gastrocystic fistula closed by metallic clips. 
demonstrated reddish granulation tissue without signs of infection ( $\bullet$ Fig. 5 ).

Throughout the period the patient received antibiotics and oral nutrition. On the seventh day, EVAT was completed by extracting the sponge without re-intubation of the cyst in order to maintain the cyst in its collapsed state. The gastrocystic fistula was closed by metallic clips (Olympus; - Fig. 6).

No complications occurred during or within 8 weeks of therapy.

In our opinion EVAT has the potential to become a new standard therapy for complicated infected pancreatic pseudocysts, because no further drainage of the cyst was necessary and the treatment of the infected pancreatic pseudocyst was completed during a single hospital stay.

Endoscopy_UCTN_Code_TTT_1AS_2AD

Competing interests: None
I. Wallstabe, A. Tiedemann, I. Schiefke Department of Gastroenterology and Hepatology, Klinikum St. Georg, Leipzig, Germany

\section{References}

1 Mathew A, Biswas A, Meitz KP. Endoscopic necrosectomy as primary treatment for infected peripancreatic fluid collections (with video). Gastrointest Endosc 2008; 68: 776 782

2 Ross AS, Kozarek RA. Therapeutic pancreatic endoscopy. Dig Liver Dis 2010; 42: 749-756

3 Will U, Wanzar C, Gerlach R et al. Interventional ultrasound-guided procedures in pancreatic pseudocysts, abscesses and infected necroses - treatment algorithm in a large single-center study. Ultraschall Med 2011; 32: $176-183$

4 Wedemeyer J, Schneider A, Manns MP, Jackobs $S$. Endoscopic vacuum-assisted closure of upper intestinal anastomotic leaks. Gastrointest Endosc 2008; 67: 708 - 711

5 Ahrens M, Schulte T, Egberts J et al. Drainage of esophageal leakage using endoscopic vacuum therapy: a prospective pilot study. Endoscopy 2010; 42: 693-698
Bibliography

DOI $10.1055 / \mathrm{s}-0030-1256643$

Endoscopy 2011; 43: E312 - E313

(c) Georg Thieme Verlag KG Stuttgart · New York . ISSN 0013-726X

\section{Corresponding author}

I. Wallstabe, MD

Department of Gastroenterology and Hepatology Klinikum St. Georg

Delitzscher Str. 141

04129 Leipzig

\section{Germany}

Fax: +49-341-9092673

wallstabe@endoskopieren.de 